\title{
Circulating miR-181a as a Potential Novel Biomarker for Diagnosis of Acute Myocardial Infarction
}

\author{
Jianbing Zhu ${ }^{\mathrm{a}}$ Kang Yao Qian Wang $^{\mathrm{b}}$ Junjie Guo ${ }^{\mathrm{a}, \mathrm{c}}$ Hongtao Shi ${ }^{\mathrm{a}}$ Leilei Ma ${ }^{\mathrm{a}}$ \\ Haibo Liu ${ }^{a}$ Wei Gao ${ }^{a}$ Yunzeng Zou ${ }^{a}$ Junbo Gea \\ aShanghai Institute of Cardiovascular Diseases, Zhongshan Hospital, Fudan University, ${ }^{b}$ Department \\ of Laboratory Medicine, Shanghai Chest Hospital affiliated to Shanghai Jiaotong University, Shanghai, \\ 'Department of Cardiology, The Affiliated Hospital of Qingdao University, Qingdao, Shandong, People's \\ Republic of China
}

\section{Key Words}

miR-181a • Biomarker • AMI

\begin{abstract}
Background: In this study, we tested the hypothesis that miR-181a levels increase during acute myocardial infarction. We investigated circulating miR-181a as a potential novel biomarker for early diagnosis of acute myocardial infarction (AMI). Methods: From June 2014 to June 2016, 120 consecutive eligible patients with AMI $(n=60)$ or unstable angina (UA; $n$ $=60$ ) and 60 control subjects were enrolled. Plasma miR-181a levels were determined by quantitative reverse transcriptase-polymerase chain reaction. Results: Circulating miR-181a expression levels detected immediately after admission were higher in the AMI group than in the UA and control groups. Relative miR-181a levels in AMI patients were positively correlated with the concentrations of the creatine kinase-MB fraction and cardiac troponin I. Correlation analysis showed that plasma miR-181a was positively correlated with coronary Gensini score $(r=0.573, P<0.05)$ and negatively correlated with left ventricular ejection fraction $(r=$ $-0.489, P<0.05)$. Receiver operating characteristic curve analyses showed that plasma miR181 a was of significant diagnostic value for AMI (AUC, $0.834 ; 95 \%$ CI, $0.756-0.912, P<0.05$ ). Conclusion: Circulating miR-181a levels in patients with AMI were significantly changed in a time-dependent manner, indicating the value of plasma miR-181a as a novel biomarker for diagnosing AMI.

\section{Introduction}

Acute myocardial infarction (AMI), one of the major causes of morbidity and mortality worldwide, is mainly caused by atherosclerosis, a chronic inflammatory response to J. Zhu and K. Yao contributed equally to this study.

Yunzeng Zou, MD, PhD

Junbo Ge, MD, PhD 


\section{Cellular Physiology Cell Physiol Biochem 2016;40:1591-1602

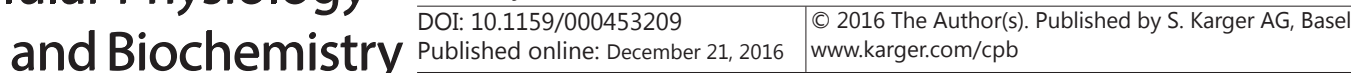 \\ Zhu et al.: miR-181a as Biomarker for Acute Myocardial Infarction}

cholesterol accumulation in the arterial wall [1]. Early diagnosis of AMI is crucial for successful treatment to protect against myocardial injury and preserve heart function [2]. AMI is a highly dynamic event associated with increased production of reactive oxygen species (ROS) [3]. The imbalance between ROS production and antioxidant defenses leads to a condition known as oxidative stress [4]. The most commonly recognized effect of increased oxidative stress is the oxidation and damage of macromolecules such as proteins, lipids, DNA, and enzymes involved in energy production, thereby contributing to cellular damage, energetic deficit, and accelerated cell death through apoptosis and necrosis [4]. Oxidative stress is a pivotal mechanism underlying myocardial ischemia injury, and inhibition targeting oxidative stress can decrease myocardial ischemia injury and preserve cardiac function [5]. Studying the possible association of oxidative stress-related biomarkers becomes relevant due to the involvement of these biomarkers in the atherosclerotic process, which may lead to the development of AMI. Early diagnosis of AMI is currently based on ischemia symptoms, physical examination, electrocardiographic examination (ECG), and circulating levels of cardiac troponins [6]. However, the measurement of circulating levels of cardiac troponins is not sufficiently sensitive and specific for use as a biochemical marker to discriminate AMI from other diseases, as slight increases may be associated with non-acute coronary syndrome and are limited to modest increases within the first few hours after AMI onset [7]. Therefore, more sensitive and specific novel biomarkers are needed to detect early AMI.

microRNAs (miRNAs) are small, endogenous, non-coding RNA molecules 21-23 nucleotides in length, which function as sequence-specific regulators of gene expression through translational repression and transcript cleavage by pairing with the $3^{\prime}$-untranslated regions (3'-UTRs) of target mRNAs [8]. Accumulating evidence has shown that miRNAs play crucial roles in numerous biological processes, including proliferation, differentiation, and apoptosis. In addition, they have been implicated in various cardiovascular diseases. Thus, circulating miRNAs may be useful as novel biomarkers for the diagnosis of AMI [9]. Furthermore, many miRNAs are remarkably stable and readily detectable in the plasma and other body fluids, and the levels of circulating miRNAs vary under specific physiological and pathological conditions, indicating that circulating miRNAs are ideal biomarkers of AMI [10].

Previous studies have shown that the levels of miR-1, miR-208a, miR-133a, and miR499 are decreased in infarcted myocardium and increased in the plasma, indicating that the elevated circulating miRNAs are released from the infarcted heart [10]. The increased levels of plasma miRNAs after AMI reflect myocardial injury and parallel the extent of myocardial damage, as measured by cardiac troponin [10]. The area under the receiver operating characteristic (ROC) curve of miR- 1 was 0.774 for AMI compared to the controls and there was a positive relationship between increased circulating miR-1 and serum creatine kinase-MB (CK-MB) [11]. A positive correlation was also reported between elevated miR-133 and cardiac troponin I (cTnI), indicating that miR-133 is superior to $\mathrm{cTnI}$ because confounding factors affect troponin I levels [12]. miR-208 was also shown to be involved in AMI, cardiomyocyte hypertrophy, fibrosis, and othercardiovasculardiseases [13]. Theincreased levels of circulating miR-499 in patients with AMI were corroborated in rat and mouse models of AMI [14].

Previous studies showed that miR-181a plays important roles in various biological events, including development, differentiation, hematopoiesis, immune modulation, and muscle adaptation to exercise [15]. miR-181a is widely expressed in several tissues, including the brain, muscle, and bone marrow, and its levels were shown to change in response to stress $[16,17]$. miR-181a is upregulated in osteosarcoma, and its overexpression promotes the proliferation and inhibits the apoptosis of osteosarcoma cells $[18,19]$. Recently, miR-181a was suggested to be a novel and important regulator of autophagy, which is a cellular catabolic mechanism activated in response to stress conditions including starvation and hypoxia during AMI [20]. Moreover, we confirmed that miR-181a inhibited the oxidized low-density lipoprotein (ox-LDL)-induced immune inflammatory response in cultured bone marrow-derived dendritic cells (DCs) in our previous study [21]. However, the specific expression patterns of circulating miR-181a in patients with AMI and their clinical significance remain unknown. Hence, determining the roles of miR-181a in AMI 


\section{Cellular Physiology Cell Physiol Biochem 2016;40:1591-1602 \begin{tabular}{l|l|l|} 
DOI: 10.1159/000453209 & $\begin{array}{l}\text { C) 2016 The Author(s). Published by S. Karger AG, Basel } \\
\text { www.karger.com/cpb }\end{array}$
\end{tabular} \\ Zhu et al.: miR-181a as Biomarker for Acute Myocardial Infarction}

would not only assist in further understanding of the pathogenesis and progression of coronary artery disease (CAD), but would also reveal novel targets for the development of effective therapies. In this study, we evaluated whether miR-181a levels increase during AMI. Our aims were to investigate the expression of circulating miR-181a in the early phase of AMI and investigate the association between plasma miR-181a levels and the severity of AMI. In addition, we also assessed the ability of circulating miR-181a to identify and evaluate AMI.

\section{Materials and Methods}

\section{Study Patients}

From June 2014 to June 2016, 120 consecutive eligible patients with AMI $(n=60)$ or UA $(n=60)$ and 60 control subjects were enrolled. The AMI inclusion criteria were ischemic chest pain lasting $>30$ min, positive biochemical markers (cardiac troponin I [cTnI] $>0.1 \mathrm{ng} / \mathrm{mL}$ ), presentation within $12 \mathrm{~h}$ after the onset of symptoms, electrocardiogram showing a new ST-segment elevation of $0.1 \mathrm{mV}$ in at least two contiguous leads [22]. All AMI patients were diagnosed for the first time and underwent primary percutaneous coronary intervention (PCI). The diagnosis of UA was based on the new onset, worsening (in frequency, intensity, or duration), or resting angina associated with evidence of ST-segment elevation or depression without evidence of myocardial necrosis based on the rise in cardiac serum markers such as CK-MB and cardiac troponin T (cTnT) or cTnI [23]. Control volunteers with normal electrocardiogram findings matched for sex, age, smoking habit, hypertension, dyslipidemia, and diabetes and without a history of AMI or UA during the same period were enrolled as control subjects. Exclusion criteria included previous myocardial infarction (MI), previous use of thrombolytic agents for index MI, cardiomyopathy, cardiogenic shock, previous stroke within the past 6 months, and known bleeding diathesis. Clinical data, including baseline clinical characteristics, angiographic, and laboratory features, and clinical outcomes, were recorded for all patients. The procedures were performed in accordance with the Declaration of Helsinki of 1975, as revised in 1983. Informed consent was obtained from all patients, and the study protocol was approved by the ethics committee of Zhongshan Hospital, Fudan University, Shanghai, China.

\section{Blood Sampling}

Whole blood samples (3-5 mL) were collected from patients with AMI at the indicated time points ( 0 h, 6 h, 12 h, 24 h, 3 days, and 7 days) after the onset of symptoms. The initial blood sample collection time (0 h) was $120 \mathrm{~min}$ (IQR: 80-520 $\mathrm{min}$ ) after the onset of chest pain symptoms (symptom-onset-todoor time). Additionally, after $0 \mathrm{~h}$, other blood samples were obtained at $6 \mathrm{~h} \pm 30 \mathrm{~min}(6 \mathrm{~h}), 12 \mathrm{~h} \pm 30$ $\min (12 \mathrm{~h}), 24 \mathrm{~h} \pm 30 \mathrm{~min}(24 \mathrm{~h}), 72 \mathrm{~h} \pm 30 \mathrm{~min}(3 \mathrm{~d})$, and $168 \mathrm{~h} \pm 30 \mathrm{~min}(7$ days). The "before PCI" blood sample collection time ("before PCI") was 80 min (IQR: 62-112 min) after the patient's admission to the emergency department (door-to-balloon time). The "after PCI" blood sample collection time ("after PCI") was $48 \mathrm{~h} \pm 30 \mathrm{~min}$ after PCI. Whole blood samples were collected from UA patients immediately after hospitalization. Samples were obtained via venipuncture of an antecubital vein and were centrifuged at $10,000 \times \mathrm{g}$ for $15 \mathrm{~min}$ at $4^{\circ} \mathrm{C}$. After separation, plasma was frozen at $-80^{\circ} \mathrm{C}$ until analysis, and $0.5 \mathrm{~mL}$ of plasma was used for RNA isolation. A full 12-h fasted lipid profile comprising total cholesterol, triglycerides, low-density lipoprotein cholesterol (LDL-C), and HDL-C was determined for each patient. cTnI, cTnT, creatine kinase (CK), and CK-MB were measured using the Access Immunoassay System (Beckman Coulter). Lipid hydroperoxide levels were evaluated based on the oxidation of $\mathrm{Fe}^{2+}$ to $\mathrm{Fe}^{3+}$ in the presence of xylenol orange and measured as the change in the absorbance at $560 \mathrm{~nm}$ [24]. Samples were calibrated using hydrogen peroxide $(0.2-20 \mathrm{mmol} / \mathrm{L})$. The limit of detection for this assay is $0.25 \mathrm{nmol} / \mathrm{L}$ [24].

\section{Percutaneous coronary intervention (PCI) procedures}

All coronary angiograms and PCI procedures were performed by experienced investigators who were blinded to the study, and transradial coronary intervention was the preferred operating approach. Coronary angiography and intervention were started within $30 \mathrm{~min}$ after admission using a radial artery approach. The following data and angiograms were estimated and collected by two operators: infarct-related artery, thrombolysis in myocardial infarction (TIMI) coronary flow before and after coronary intervention, extent of coronary artery disease, and left ventricular function. Stents were placed when residual stenosis $>50 \%$ was 


\section{Cellular Physiology Cell Physiol Biochem 2016;40:1591-1602 \begin{tabular}{l|l|l} 
and BOI: 10.1159/000453209 & $\begin{array}{l}\text { C) 2016 The Author(s). Published by S. Karger AG, Basel } \\
\text { www.karger.com/cpb }\end{array}$ \\
\hline
\end{tabular} \\ Zhu et al.: miR-181a as Biomarker for Acute Myocardial Infarction}

present after balloon angioplasty. TIMI flow grade was determined by assessing blood flow in the epicardial arteries. The procedural success was definedas residual stenosis atless than $20 \%$ and TIMIflowgrade of 2 in the infarct-relatedarteryafter PCI.TheGensiniscorewasused toassess theseverityof coronaryarterystenosis [25].

Quantitative real-time polymerase chain reaction ( $q R T-P C R$ )

Plasma miR-181a levels were determined by quantitative reverse transcriptase-polymerase chain reaction (qRT-PCR) [26]. Total RNA was extracted from the plasma using TRIzol reagent (Invitrogen, Carlsbad, CA, USA) according to the manufacturer's instructions. qRT-PCR was performed on cDNA generated from $50 \mathrm{ng}$ of total RNA using the TaqMan ${ }^{\circledR}$ MicroRNA Assay kit (Applied Biosystems, Foster City, CA, USA) according to the manufacturer's instructions. qRT-PCR was performed in triplicate using an ABI Prism 7500 sequence detection system (Applied Biosystems). The amplification reaction was as follows: $94^{\circ} \mathrm{C}$ for $5 \mathrm{~min}$ and 30 cycles of $94^{\circ} \mathrm{C}$ for $30 \mathrm{~s}, 55^{\circ} \mathrm{C}$ for $30 \mathrm{~s}$, and $72^{\circ} \mathrm{C}$ for $30 \mathrm{~s}$. The cycle number at which the fluorescent signal of the sample rose above the baseline was referred to as the threshold cycle $(\mathrm{Ct})$ and was proportional to the target concentration. Relative gene expression was calculated by comparing the cycle times for each target gene. The target gene Ct values were normalized by subtracting the U6 Ct value, and the relative expression level between groups was calculated according to the $2^{-}$ $\Delta \Delta \mathrm{Ct}$ method, as follows: relative gene expression $=2^{-(\Delta \mathrm{Ct} \text { sample }-\Delta \mathrm{Ct} \text { control) }}$ [27]. The primers used were as follows: U6 forward, 5'-GCTTCGGCAGCACATATACTAA-3', U6 reverse, 5'-AACGCTTCACGAATTTGCGT-3'; miR-181a forward, 5'-AACATTCAACGCTGTCG-3', and miR-181a reverse, 5'-AACTGGTGTCGTGGAG-3'.

\section{Statistical analysis}

Statistical analysiswas performed using SPSS 20.0 software (SPSS, Inc., Chicago, IL, USA). Continuous data are presented as the mean \pm SD. Categorical variables are presented as counts and percentages. Independent sample $t$-tests and Mann-Whitney U tests were performed to compare groups of continuous variables. Categorical variables were compared by chi-square test. ROC curve analysis and comparison of the derived area under the curve (AUC) were performed to assess themiRNA as a predictor for distinguishing AMI from non-AMI. Correlations between variables were determined by Spearman tests. Statistical significance was set at $P<0.05$.

\section{Results}

Circulating miR-181a levels were increased in patients with AMI

Sixty AMI patients, 60 UA patients, and 60 control subjects were enrolled in this study. The baseline clinical characteristics of the patients and controls are presented in Table 1. The baseline clinical data of the three groups, including age, body mass index, sex, risk factors, total cholesterol, TG, high-density lipoprotein-C, LDL-C, Lp(a), and

Table 1. Baseline Clinical Characteristics of Patients and Controls. Values are mean \pm SD or absolute numbers with relative frequencies. BMI, body mass index; TC, total cholesterol; TG, triglyceride; LDL-C, low-density lipoprotein cholesterol; HDL-C, high-density lipoprotein cholesterol; Lp(a), lipoprotein (a); ACEI, angiotensin converting enzyme inhibitors; ARB, angiotensin receptor blockers; CCB, calcium channel blockers;

\begin{tabular}{lllll}
\hline Variable & $\begin{array}{l}\text { AMI } \\
(n=60)\end{array}$ & $\begin{array}{l}\text { UA } \\
(n=60)\end{array}$ & $\begin{array}{l}\text { Control } \\
(n=60)\end{array}$ & $\begin{array}{l}\text { P value } \\
\text { (AMI vs. UA vs. } \\
\text { Control) }\end{array}$ \\
\hline Male & $46(76.7 \%)$ & $42(70.0 \%)$ & $45(75.0 \%)$ & 0.492 \\
BMI $\left(\mathrm{kg} / \mathrm{m}^{2}\right)$ & $24 \pm 2.5$ & $25 \pm 2.6$ & $25 \pm 2.1$ & 0.562 \\
Age (years) & $64.1 \pm 10.3$ & $62.1 \pm 11.2$ & $63.2 \pm 12.2$ & 0.634 \\
Risk factors & & & & \\
Hypertension & $26(43.3 \%)$ & $24(40.0 \%)$ & $27(45.0 \%)$ & 0.472 \\
Diabetes mellitus & $15(25.0 \%)$ & $16(26.7 \%)$ & $12(20.0 \%)$ & 0.153 \\
Dyslipidemia & $29(48.3 \%)$ & $26(43.3 \%)$ & $28(46.7 \%)$ & 0.465 \\
Smoking & $38(63.3 \%)$ & $40(66.7 \%)$ & $39(65.0 \%)$ & 0.486 \\
TC (mmol/L) & $4.20 \pm 0.90$ & $4.06 \pm 1.0$ & $3.99 \pm 0.85$ & 0.361 \\
TG (mmol/L) & $1.53 \pm 0.97$ & $1.48 \pm 0.95$ & $1.42 \pm 0.89$ & 0.456 \\
LDL-C (mmol/L) & $2.51 \pm 0.75$ & $2.48 \pm 0.68$ & $2.31 \pm 0.79$ & 0.287 \\
HDL-C (mmol/L) & $1.13 \pm 1.01$ & $1.16 \pm 0.95$ & $1.24 \pm 0.89$ & 0.531 \\
Lp(a) (mg/L) & $223.42 \pm 130.26$ & $212.56 \pm 126.20$ & $218.65 \pm 128.56$ & 0.486 \\
Peak CK-MB (IU/L) & $282.7 \pm 89.6$ & $16.8 \pm 5.7$ & $9.9 \pm 6.4$ & $<0.001$ \\
Peak CK (IU/L) & $1642 \pm 903$ & $102 \pm 42$ & $82 \pm 55$ & $<0.001$ \\
cTnI (ng/mL) & $21.5 \pm 7.3$ & $0.02 \pm 0.01$ & 0 & $<0.001$ \\
Medications & & & & \\
$\beta$-blockers & $18(30.0 \%)$ & $16(26.7 \%)$ & - & 0.289 \\
ACEI & $12(20.0 \%)$ & $10(16.7 \%)$ & - & 0.312 \\
ARB & $13(21.7 \%)$ & $15(25.0 \%)$ & - & 0.576 \\
CCB & $9(15.0 \%)$ & $7(11.7 \%)$ & - & 0.259 \\
Nitrates & $19(31.7 \%)$ & $16(26.7 \%)$ & - & 0.350 \\
Statins & $38(63.3 \%)$ & $42(70.0 \%)$ & - & \\
\hline
\end{tabular}


Fig. 1. Circulating miR-181a expression levels in the AMI, UA, and control groups. A, Comparison of plasma miR-181a levels in AMI, UA, and control groups. B, Plasma levels of miR181a in AMI patients at the indicated times after symptom onset. Data are presented as the mean $\pm \mathrm{SD} ;{ }^{*} P$ $<0.05$ compared to the value at 0 h. C, Correlations between plasma miR-181a levels and CK-MB concentrations in AMI patients $(\mathrm{r}=0.514$, $P<0.05$ ). D, Correlations between plasma miR-181a levels and cTnI concentrations in AMI patients $(\mathrm{r}=$ $0.432, P<0.05)$. AMI, acute myocardial infarction; UA, unstable angina.

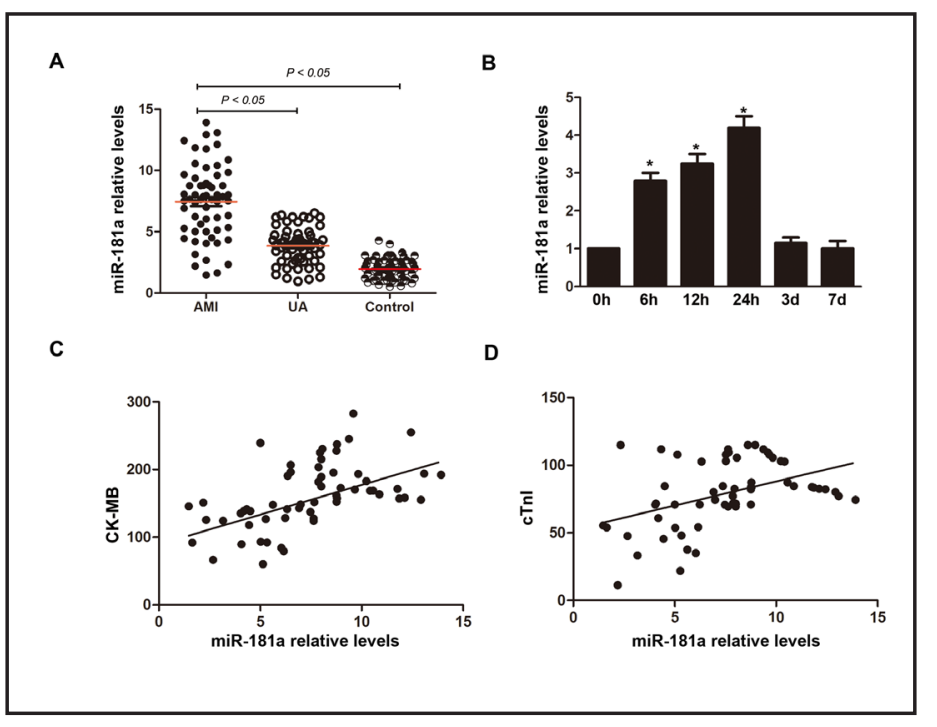

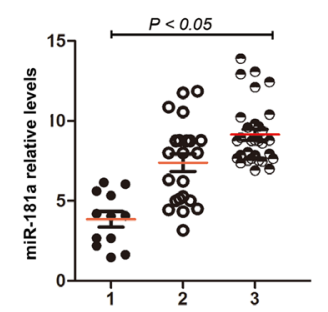

C

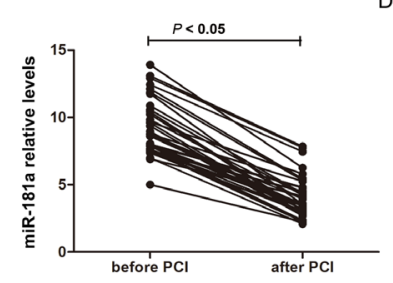

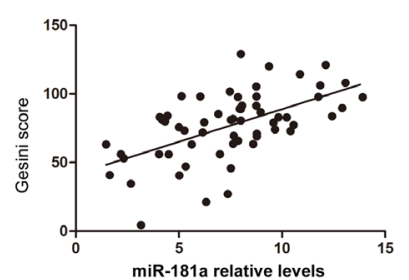

D

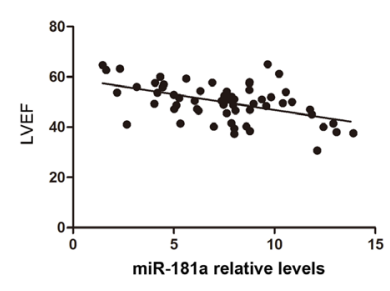
dial infarction.

medications, did not differ significantly among groups. Blood samples were obtained from AMI patients at the indicated time points $(0 \mathrm{~h}, 6 \mathrm{~h}, 12 \mathrm{~h}, 24 \mathrm{~h}, 3$ days, and 7 days $)$ after the onset of AMI. Gender-specific (adjusted OR 1.206, 95\% CI 0.86-1.897, $P>0.05$ ) was not significant differences correlated with increase in plasma miR-181a expression levels by the multivariate logistic regression analysis. Plasma miR-181a expression levels detected immediately after admission were higher in the AMI group than in the UA and control groups (Fig. 1A, $P<0.05$ ). As shown in Fig. 1B, the relative plasma miR-181a levels at 6 $\mathrm{h}, 12 \mathrm{~h}$, and $24 \mathrm{~h}$ after the onset of AMI were higher than those at $0 \mathrm{~h}(P<0.05)$; at 3 days and 7 days, the levels were similar to those at $0 \mathrm{~h}(P>0.05)$. Correlation analyses between plasma miR-181a levels and CK-MB and cTnI concentrations are shown in Fig. 1C and Fig. 1D, respectively. The relative miR-181a levels in AMI patients were positively correlated with the serum concentrations of CK-MB $(r=0.514, P<0.05)$ and cTnI $(r=0.432, P<0.05)$. 
A

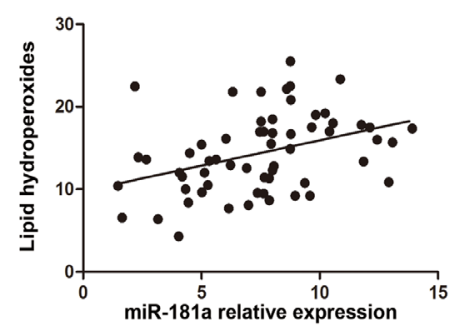

B

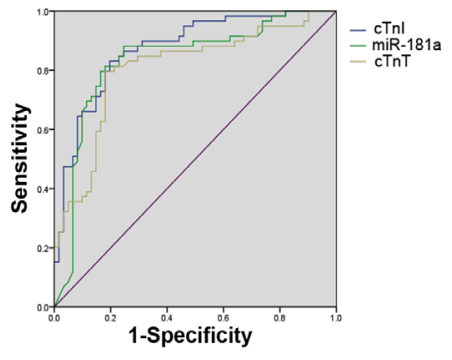

Fig. 3. Plasma miR-181a levels as a novel biomarker for the diagnosis of AMI. A, Correlation between plasma miR-181a levels and lipid hydroperoxide concentrations in AMI patients ( $r=0.382, P<0.05)$. B, ROC curve analysis of plasma miR-181a to predict AMI. ROC, receiver operating characteristic curve; AMI, acute myocardial infarction; cTnI, cardiac troponin I.

\section{Circulating miR-181a levels in AMI patients undergoing PCI}

The door-to-balloon time (D2BT) and symptom-onset-to-door time observed in AMI patients undergoing PCI were $80 \mathrm{~min}$ (IQR: 62-112 min) and $120 \mathrm{~min}$ (IQR: 80 - $520 \mathrm{~min}$ ), respectively, and $70.8 \%$ of patients had D2BT $<90$ min. As shown in Fig. 2A, significantly higher miR-181a levels were detected in AMI patients with two- and three-vessel lesions than in patients with single-vessel lesions $(P<0.05)$. Correlation analysis showed that plasma miR-181a was positively correlated with coronary Gensini score $(r=0.573, P<0.05)$, which is used to evaluate the severity of coronary stenotic lesions (Fig. 2B). Plasma miR181a levels in AMI patients at $48 \mathrm{~h}$ after PCI were significantly lower than in the before PCI group $(P<0.05$; Fig. 2C). Furthermore, miR-181a levels were negatively correlated with left ventricular ejection fraction by correlation analysis $(r=-0.489, P<0.05$; Fig. 2D).

Circulating miR-181a levels and oxidative stress parameters

We evaluated whether miR-181a levels were correlated with oxidative stress parameters in AMI patients. Correlations analyses showed that miR-181a was positively correlated with lipid hydroperoxide concentrations $(r=0.382, P<0.05$; Fig. $3 \mathrm{~A})$.

\section{Evaluation of plasma miR-181 a as novel diagnostic biomarker of AMI}

ROC analysis was performed to determine the suitability of miR-181a as a biomarker of AMI. The ROC curves of plasma miR-181a showed separation between the AMI and nonAMI groups, with an AUC of 0.834 (95\% CI, 0.756-0.912, $P<0.05)$, compared to cTnI with an AUC of 0.873 (95\% CI, 0.810-0.936, $P<0.05$; Fig. 3B), and cTnT with an AUC of 0.816 (95\% CI, 0.735-0.897, $P<0.05$; Fig. 3B). The ROC curves revealed that the cut-off value of plasma miR-181a differentiating AMI patients from non-AMI subjects was 2.869 . The specificity and sensitivity of miR-181a for the diagnosis of AMI were 0.826 and 0.898 , respectively. These data indicate that circulating miR-181a can be used as a novel diagnostic biomarker of AMI.

\section{Discussion}

Highly sensitive, reliable, early diagnosis of AMI is required for prompt PCI therapy, which may improve the survival rate of patients of AMI. Although it is unlikely that a single biomarker of myocardial ischemic injury will be sufficient to manage AMI diagnosis, a combination of different biomarkers, including circulating miRNAs, may enhance diagnostic sensitivity and specificity [28]. Numerous circulating miRNAs, including miR-208a, miR-126, miR-223-3p, miR-150, miR-19b-3p, miR-21, miR-328, and miR-134, showed potential as biomarkers for cardiovascular diseases [28-34].

The present study indicates that plasma miR-181a is a useful diagnostic biomarker for AMI. In our study, plasma concentrations of miR-181a were significantly elevated at 6 h, 12 
$\mathrm{h}$, and $24 \mathrm{~h}$ after the onset of symptoms. The relative levels of miR-181a in patients with AMI were positively correlated with the concentrations of CK-MB and CTnI. ROC curve analyses revealed that plasma miR-181a was of significant diagnostic value for AMI (AUC, 0.834; $95 \% \mathrm{CI}, 0.756-0.912, P<0.05)$. Although the diagnostic value of miR-181a was inferior to that of cTnI (AUC, $0.873 ; 95 \% \mathrm{CI}, 0.810-0.936, P<0.05$ ), it may be a promising novel biomarker for enhancing diagnostic sensitivity when combined with classical biomarkers.

Previous studies demonstrated that numerous circulating miRNAs are altered in AMI, including the cardiac-specific miRNAs miR-208 and miR-499 [35-40]. However, miRNAs dysregulated in AMI may also be derived from non-myocardium cells that play a vital role in AMI pathophysiology, such as endothelial cells involved in plaque rupture and inflammatory cells that are recruited to the ischemic area [35]. The endothelium-enriched miRNA miR-126 was shown to be useful as a biomarker in AMI, and plasma miR-126 and cTnI expression levels showed the same trends [41]. The inflammation-associated miRNA miR-155 was significantly lower in patients with coronary artery disease than in control subjects [42]. Further studies are needed to determine whether the expression of these miRNAs is correlated with that of miR-181a. Increased reactive oxygen species (ROS) production is involved in adverse cardiac remodeling and development of heart failure after MI. Recently, Magenta et al demonstrated thatROSincreased cytosolic [Ca ${ }^{2+}$, (Cai) and modulated the expression of miR-181a and miR-1, indicating that both miR-181a and miR-1 affect Cai-dependent intracellular signaling during oxidative stress [43]. In silico prediction of target genes by miRanda, miRdB, and TargetScan and subsequent qPCR analysis revealed that miRNAs including miR-208a, miR-133, and miR-181a target genes that primarily regulate cell proliferation and cell death during heart failure [44]. Furthermore, combining plasma miR-181a with other miRNAs in a panel should be established to increase the efficiency of distinguishing patients with AMI and controls.

Symptom onset is associated with the kinetics of plasma miRNA levels in AMI patients, and an advantage of circulating miRs compared to traditional biomarkers may be their early release after symptom onset [45]. Muscle-derived miR-499-5p was shown to be elevated by 1.7-fold as early as 15 min after the induction of coronary artery ligation in mice [35]. In humans, miR-1 and miR-133 were identified to be elevated as early as 156 min after the onset of symptoms and decreased thereafter, whereas miR-499 further increased, achieving maximal levels by approximately $9 \mathrm{~h}$ after symptom onset [35]. Because of the variability in symptom onset after AMI in patients, however, these data, including our results, should be considered with caution and further studies are required to monitor the kinetics of miRs release in comparison to CK, CK-MB, and troponins. Moreover, whether specific miRs are released very early after the onset of symptoms within microvesicles or exosomes, indicating the initiating processes of cellular inflammation or apoptosis during myocardial ischemia and injury, must be further examined. In the present study, the D2BT and symptom-onset-to-door time observed in AMI patients undergoing PCI were $80 \mathrm{~min}$ (IQR: $62-112 \mathrm{~min}$ ) and $120 \mathrm{~min}$ (IQR: 80-520 $\mathrm{min}$ ), respectively, and $70.8 \%$ of patients showed D2BT $<90$ min. Our results demonstrate that plasma miR-181a is elevated at $6 \mathrm{~h}$ as well as at $12 \mathrm{~h}$ or at $24 \mathrm{~h}$, and decreased at 3 days and 7 days after the onset of symptoms, suggesting that miR-181a is released in a time-dependent manner.

AMI is mainly caused by atherosclerosis, which is considered a chronic inflammatory response to cholesterolaccumulation in thearterialwall.In atheroscleroticlesions, DCs, theonly professional and most powerful antigen-presenting cells, accumulated in the subendothelium and underwent maturation stimulated by ox-LDL, advanced glycosylation end products, or other antigen components [46]. CD11 $\mathrm{c}^{+}$DCs from ApoE ${ }^{-/}$mice with hyperlipidemia showed increased inflammatory responses and upregulated miR-181a expression [21]. miR-181a feedback attenuated the ox-LDL-stimulated immune inflammatory response by targeting c-Fos in DCs, suggesting its important diagnostic value for coronary artery disease [21]. miR181a downregulated IL- 6 and TNF- $\alpha$ and inhibited ox-LDL-induced increases in IL- 6 and TNF- $\alpha$ in DCs [21]. The present study demonstrated that plasma concentrations of miR-181a were significantly increased after the onset of symptoms in patients with AMI, which may be significantly associated with the immune inflammatory response in atherosclerotic lesions.

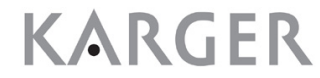


cTnI is also expressed in the skeletal muscle and is elevated by skeletal muscle injury during operation, which diminishes the value of cTnI elevation caused by myocardial injury [7]. In addition, the sensitivity and specificity of CK-MB and other conventional markers must be further enhanced, and it is difficult to identify new proteomic markers because of a technical bottleneck [47]. miRNAs are highly stable in vitro, can be detected by qRT-PCR, and can be used in remarkably sensitive and specific testing for the early diagnosis of AMI [48]. Our study confirmed that plasma miR-181a was of significant diagnostic value for AMI (AUC, $0.834 ; 95 \%$ CI, $0.756-0.912, P<0.05$ ), similarly to cTnI (AUC, $0.873 ; 95 \%$ CI, $0.810-0.936, P<0.05$ ). Based on the results of the present study, miRNAs may be useful as sensitive, specific circulating biomarkers for the diagnosis of AMI. miR-181a is not correlated with known biochemical indicators of AMI. Therefore, miR-181a levels in the circulation are closely associated with the occurrence of AMI and may be an independent biomarker for the early diagnosis of AMI.

Oxidative stress may play an etiological role in AMI and be useful as a biomarker [49]. When oxidative stress occurs, cells trigger a series of biochemical cascades to alter the redox balance and restore homeostasis following the development of atherosclerotic plaques and subsequent AMI [49]. During AMI, the miRNAs involved in inflammation may be indicators of the oxidative-stress response that maintains cellular homeostasis under ischemic and hypoxic conditions [50]. miR-210 was closely related to oxidative stress regulation, and inhibition of miR-210 led to increased apoptosis and oxidative tissue injury [51]. We measured the plasma levels of miR-181a in patients with AMI at various time points and correlated them with oxidative stress as measured by lipid hydroperoxides. Correlation analyses showed that miR-181a was positively correlated with lipid hydroperoxide concentration $(r=0.382, P<0.05)$. Thus, miR-181a may be an indicator of the adaptive response to reduce oxidative stress in patients with AMI.

The Gensini score indicates the severity of AMI, which facilitates identification of the optimal PCI strategy for patients with AMI [52]. However, calculating the Gensini score is considered difficult and time-consuming. Therefore, it is necessary to identify biomarkers that can accurately reflect the severity of coronary vessel lesions in patients with AMI. We found that plasma miR-181a was positively correlated with the severity of coronary stenosis as measured by Gensini score. These results further indicate that miR-181a release from inflammatory cells reflects the risk of myocardial ischemia and injury. Our results confirmed that plasma miR-181a levels in patients with AMI were significantly lower after PCI compared to the levels before PCI, indicating that miR181a is an ideal biomarker for predicting myocardial ischemia reperfusion in patients with AMI. Additionally, miR-181a levels were negatively correlated with left ventricular ejection fraction, indicating poor prognosis and an increased risk of heart failure.

In the present study, multivariate logistic regression analysis was performed to adjust for gender-specific differences. Gender-specific differences (adjusted OR 1.206, 95\% CI 0.86-1.897, $P>0.05$ ) were not significant differences correlated with increased plasma miR-181a expression levels and there were similar trends for kinetics of plasma miR-181a in both male and female patients according to multivariate logistic regression analysis. Gender is an important determinant of cardiovascular risk, and men generally develop cardiovascular disease earlier than women [53]. AMI is the main cause of mortality in men and the incidence increases with age in both genders, but for men the increase is more pronounced [53]. The incidence of coronary artery disease is 3-4-fold higher in men than in women; a male predominance was also found in the incidence of myocardial infarction in industrialized countries, which is consistent with the gender differences determined in our study [54]. In the Framingham cohort, 797 cardiovascular events occurred during 16-year median follow-up among men; 571 events occurred over 19-year median followup among women. In the cohorts from China, 254 and 99 events were recorded in men and women, respectively, during the first 8 years of follow-up [55]. There are also gender differences within the spectrum of coronary heart disease and men have higher risk of AMI [56]. The gender gap in coronary artery disease may be influenced by two characteristics of risk factors. First, the prevalence of risk factors for CHD in the population may vary 
between men and women. Atherogenic risk factors that are more prevalent in men or protective factors that are more prevalent in women are expected to contribute to a higher incidence of disease in men than in women [57]. Cardiovascular risk factors such as smoking, obesity, and hypertension and higher levels of blood glucose and lipids were more prevalent in men [58]. Second, women may be biologically protected from a particular risk factor compared with men, resulting in the greater susceptibility of men or resistance of women to the same level of the risk factor [57]. The burden of coronary heart disease is consistently higher in men, but gender differences in lifestyle and acquired risk factors do not fully explain this disparity [56]. Sex-specific data focused on cardiovascular disease have increased, but this information is not routinely collected or translated into practice.

These single-center results may not be easily extrapolated. Therefore, additional studies with larger cohorts of patients with AMI and control subjects are needed to validate the diagnostic value of miR-181a as a practical biomarker. Most previous studies have been limited by conducting more broad measurements in very small numbers of individuals. However, Freedman et al recently presented comprehensive data demonstrating the broad and consistent detection of numerous classes of circulating miRNAs from diverse genetic backgrounds with a large population including 2763 participants, which presents the largest description of plasma-based miRNAs in a large population [59]. They found that nearly 500 of the most abundant extracellular transcripts such as miRNA and piRNA were expressed in almost all participants [59]. These findings show that diverse classes of circulating miRNAs, including hsa-miR-181a-5p, are consistently present in the plasma from multiple human populations [59]. hsa-miR-181a-5p was expressed in nearly all participants with mean ( \pm s.d.) Ct values of $19.39 \pm 1.50$ and sex (OR 0.96, 95\% CI 0.84-1.09, $P=0.5$ ) and age (OR $1.08,95 \%$ CI $0.95-1.23, P=0.2$ ) were not significantly correlated with plasma miR-181a expression levels [59]. These results from the diverse populations are consistent with our results in a small single center study in China. Although we assessed plasma miR-181a levels immediately after admission and after PCI, serial measurements of miR-181a may be more useful for evaluating changes in inflammatory status, estimating risk during the follow-up period, and directing in- and out-patient treatments. Further studies are required to clarify the value of miR-181a for prognostic prediction of AMI.

The mechanism by which miR-181a is involved in the regulation of oxidative stress and inflammatory response and associated with infarction is predicted as follows. Oxidative stress, defined as excess ROS production, plays an important role in the pathophysiology of cardiac remodeling including cell death and contractile dysfunction during myocardial infarction. First, $\mathrm{Ca}^{2+}$ and ROS signaling interact: $\mathrm{Ca}^{2+}$ can increase ROS production, and ROS can significantly affect $\mathrm{Ca}^{2+}$ influx into the cell and intracellular $\mathrm{Ca}^{2+}$ stores. miR-181a was associated with increased cell susceptibility to oxidative and endoplasmic reticulum stresses via the suppression of ischemia-induced cytosolic [ $\mathrm{Ca}^{2+}$ [43]. Second, miR-181a, which has been reported to play a vital role during the inflammatory response in the cardiovascular system, protects the system from inflammation injury by interfering NF- $\kappa \mathrm{B}$ functioning and cell proliferation during oxidative stress [60]. Finally, miR-181a can attenuate ox-LDLstimulated immune inflammation responses by targeting c-Fos in DCs and maintain the fate of immune cells by regulating Toll-like receptor signaling in innate immunity [21,61].

In summary, the present study showed that circulating miR-181a levels in patients with AMI were significantly altered in a time-dependent manner. This indicates the value of plasma miR-181a as a novel biomarker for the diagnosis of AMI. Additional studies are needed to clarify the value of miR-181a for the diagnosis and prognostic prediction of AMI.

\section{Acknowledgements}

This study was supported by the General Program (Key Program, Major Research Plan) of the National Natural Science Foundation of China (Grant No. 81230007) and the National Natural Science Fund of China (Grant Nos. 81470386 and 81400263). 


\section{Cellular Physiology Cell Physiol Biochem 2016;40:1591-1602 \begin{tabular}{l|l|l} 
and Biochemistry $\begin{array}{l}\text { DOI: 10.1159/000453209 } \\
\text { Published online: December 21, } 2016\end{array}$ & $\begin{array}{l}\text { (c) } 2016 \text { The Author(s). Published by S. Karger AG, Basel } \\
\text { www.karger.com/cpb }\end{array}$
\end{tabular} \\ Zhu et al.: miR-181a as Biomarker for Acute Myocardial Infarction}

\section{Disclosure Statement}

The authors declared no conflicts of interest.

\section{References}

1 Yeh RW, Sidney S, Chandra M, Sorel M, Selby JV, Go AS: Population trends in the incidence and outcomes of acute myocardial infarction. N Engl J Med 2010;362:2155-2165.

2 White, HD, Chew, DP: Acute myocardial infarction. Lancet 2008; 372: 570-584.

3 Ibanez B, Heusch G, Ovize M, Van de Werf F: Evolving therapies for myocardial ischemia/reperfusion injury. J Am Coll Cardiol 2015;65:1454-1471.

4 Giordano FJ: Oxygen, oxidative stress, hypoxia, and heart failure. J Clin Invest 2005; 115:500-508.

5 Heusch G: Cardioprotection: chances and challenges of its translation to the clinic. Lancet 2013;381:166175.

6 White HD, Thygesen K, Alpert JS, Jaffe AS: Clinical implications of the Third Universal Definition of Myocardial Infarction. Heart 2014;100:424-432.

7 Agewall S, Giannitsis E, Jernberg T, Katus H: Troponin elevation in coronary vs. non-coronary disease. Eur Heart J 2011;32:404-411.

8 Bartel DP: MicroRNAs: target recognition and regulatory functions. Cell 2009;136:215-233.

9 Small EM, Olson EN: Pervasive roles of microRNAs in cardiovascular biology. Nature 2011;469:336-342.

10 Li C, Pei F, Zhu X, Duan DD, Zeng C: Circulating microRNAs as novel and sensitive biomarkers of acute myocardial Infarction. Clin Biochem 2012;45:727-732.

11 Cheng Y, Tan N, Yang J, Liu X, Cao X, He P, Dong X, Qin S, Zhang C: A translational study of circulating cellfree microRNA-1 in acute myocardial infarction. Clin Sci (Lond) 2010;119:87-95.

12 Freda BJ, Tang WH, Van Lente F, Peacock WF, Francis GS: Cardiac troponins in renal insufficiency: review and clinical implications. J Am Coll Cardiol 2002;40:2065-2071.

13 Callis TE, Pandya K, Seok HY, Tang RH, Tatsuguchi M, Huang ZP, Chen JF, Deng Z, Gunn B, Shumate J, Willis MS, Selzman CH, Wang DZ: MicroRNA-208a is a regulator of cardiac hypertrophy and conduction in mice. J Clin Invest 2009;119:2772-2786.

14 Adachi T, Nakanishi M, Otsuka Y, Nishimura K, Hirokawa G, Goto Y, Nonogi H, Iwai N: Plasma microRNA 499 as a biomarker of acute myocardial infarction. Clin Chem 2010;56:1183-1185.

15 Seoudi AM, Lashine YA, Abdelaziz AI: MicroRNA-181a - a tale of discrepancies. Expert Rev Mol Med 2012;14:e5.

16 Belkaya S, Silge RL, Hoover AR, Medeiros JJ, Eitson JL, Becker AM, de la Morena MT, Bassel-Duby RS, van Oers NS: Dynamic modulation of thymic microRNAs in response to stress. PLoS One 2011;6:e27580.

17 Chen CZ, Li L, Lodish HF, Bartel DP: MicroRNAs modulate hematopoietic lineage differentiation. Science 2004;303:83-86.

18 Zhu ZJ, Huang P, Chong YX, Kang LX, Huang X, Zhu ZX, Nie L: MicroRNA-181a promotes proliferation and inhibits apoptosis by suppressing CFIm25 in osteosarcoma. Mol Med Rep DOI:10.3892/mmr.2016.5741.

19 Jianwei Z, Fan L, Xiancheng L, Enzhong B, Shuai L, Can L: MicroRNA 181a improves proliferation and invasion, suppresses apoptosis of osteosarcoma cell. Tumour Biol 2013;34:3331-3337.

20 Tekirdag KA, Korkmaz G, Ozturk DG, Agami R, Gozuacik D: MIR181A regulates starvation- and rapamycininduced autophagy through targeting of ATG5. Autophagy 2013;9:374-385.

21 Wu C, Gong Y, Yuan J, Zhang W, Zhao G, Li H, Sun A, KaiHu, Zou Y, Ge J: microRNA-181a represses ox-LDLstimulated inflammatory response in dendritic cell by targeting c-Fos. J Lipid Res 2012;53:2355-2363.

22 Steg PG, James SK,Atar D, Badano LP, Blömstrom-Lundqvist C, Borger MA, Di Mario C, Dickstein K, Ducrocq G, Fernandez-Aviles F, Gershlick AH, Giannuzzi P, Halvorsen S, Huber K, Juni P, Kastrati A, Knuuti J, Lenzen MJ, Mahaffey KW, Valgimigli M, van 't Hof A, Widimsky P, Zahger D: ESC Guidelines for the management of acute myocardial infarction in patients presenting with ST-segment elevation. Eur Heart J 2012;33:25692619.

23 Cayla G, Silvain J, Collet JP, Montalescot G: Updates and current recommendations for the management of patients with non-ST-elevation acute coronary syndromes: what it means for clinical practice. Am J Cardiol 2015;115:10A-22A. 


\section{Cellular Physiology Cell Physiol Biochem 2016;40:1591-1602 and Biochemistry Published online: December 21, $2016 \quad \begin{aligned} & \text { DOI: 10.1159/000453209 } 2016 \text { The Author(s). Published by S. Karger AG, Basel } \\ & \text { www.karger.com/cpb }\end{aligned}$ \\ Zhu et al.: miR-181a as Biomarker for Acute Myocardial Infarction}

24 Mikhed Y, Gorlach A, Knaus UG, Daiber A: Redox regulation of genome stability by effects on gene expression, epigenetic pathways and DNA damage/repair. Redox Biol 2015;5:275-289.

25 Gensini GG: A more meaningful scoring system for determining the severity of coronary heart disease. Am J Cardiol 1983;51:606.

26 Chen C, Ridzon DA, Broomer AJ, Zhou Z, Lee DH, Nguyen JT, Barbisin M, Xu NL, Mahuvakar VR, Andersen MR, Lao KQ Livak KJ, Guegler KJ: Real-time quantification of microRNAs by stem-loop RT-PCR. Nucleic Acids Res 2005;33:e179.

27 Tsui NB, Ng EK, Lo YM: Molecular analysis of circulating RNA in plasma. Methods Mol Biol 2006;336:123134.

28 Lainscak M, Anker MS, von Haehling S, Anker SD: Biomarkers for chronic heart failure: diagnostic, prognostic, and therapeutic challenges. Herz 2009;34:589-593.

29 Yan X, Liu J, Wu H, Liu Y, Zheng S, Zhang C, Yang C: Impact of miR-208 and its Target Gene Nemo-Like Kinase on the Protective Effect of Ginsenoside Rb1 in Hypoxia/Ischemia Injuried Cardiomyocytes. Cell Physiol Biochem 2016;39:1187-1195.

30 Li HY, Zhao X, Liu YZ, Meng Z, Wang D, Yang F, Shi QW: Plasma MicroRNA-126-5p is Associated with the Complexity and Severity of Coronary Artery Disease in Patients with Stable Angina Pectoris. Cell Physiol Biochem 2016;39:837-846.

31 Liu X, Zhang Y, Du W, Liang H, He H, Zhang L, Pan Z, Li X, Xu C, Zhou Y, Wang L, Qian M, Liu T, Yin H, Lu Y, Yang B, Shan H: MiR-223-3p as a Novel MicroRNA Regulator of Expression of Voltage-Gated K+ Channel Kv4.2 in Acute Myocardial Infarction. Cell Physiol Biochem 2016;39:102-114.

32 Deng P, Chen L, Liu Z, Ye P, Wang S, Wu J, Yao Y, Sun Y, Huang X, Ren L, Zhang A, Wang K, Wu C, Yue Z, Xu X, Chen M: MicroRNA-150 Inhibits the Activation of Cardiac Fibroblasts by Regulating c-Myb. Cell Physiol Biochem 2016;38:2103-2122.

33 Wang KJ, Zhao X, Liu YZ, Zeng QT, Mao XB, Li SN, Zhang M, Jiang C, Zhou Y, Qian C, Feng KG, Guan HQ Tang TT, Cheng X, Chen ZJ: Circulating MiR-19b-3p, MiR-134-5p and MiR-186-5p are Promising Novel Biomarkers for Early Diagnosis of Acute Myocardial Infarction. Cell Physiol Biochem 2016;38:1015-1029.

34 Li S, Fan Q, He S, Tang T, Liao Y, Xie J: MicroRNA-21 negatively regulates Treg cells through a TGF- $\beta 1 /$ Smadindependent pathway in patients with coronary heart disease. Cell Physiol Biochem 2015;37:866-878.

35 D'Alessandra Y, Devanna P, Limana F, Straino S, Di Carlo A, Brambilla PG, Rubino M, Carena MC, Spazzafumo L, De Simone M, Micheli B, Biglioli P,Achilli F, Martelli F, Maggiolini S, Marenzi G, Pompilio G, Capogrossi MC: Circulating microRNAs are new and sensitive biomarkers of myocardial infarction. Eur Heart J 2010;31:2765-2773.

36 Xu Y, Zhu W, Wang Z, Yuan W, Sun Y, Liu H, Du Z: Combinatorial microRNAs suppress hypoxia-induced cardiomyocytes apoptosis. Cell Physiol Biochem 2015;37:921-932.

37 Xu Y, Zhu W, Sun Y, Wang Z, Yuan W, Du Z: Functional Network Analysis Reveals Versatile MicroRNAs in Human Heart. Cell Physiol Biochem 2015;36:1628-1643.

38 Wang Y, Men M, Yang W, Zheng H, Xue S: MiR-31 Downregulation Protects Against Cardiac Ischemia/ Reperfusion Injury by Targeting Protein Kinase C Epsilon (PKCE) Directly. Cell Physiol Biochem 2015;36:179-190.

39 Zhao X, Wang K, Liao Y, Zeng Q, Li Y, Hu F, Liu Y, Meng K, Qian C, Zhang Q, Guan H, Feng K, Zhou Y, Du Y, Chen Z: MicroRNA-101a inhibits cardiac fibrosis induced by hypoxia via targeting TGFßRI on cardiac fibroblasts. Cell Physiol Biochem 2015;35:213-226.

40 Melo SF, Fernandes T, Baraúna VG, Matos KC, Santos AA, Tucci PJ, Oliveira EM: Expression of MicroRNA-29 and Collagen in Cardiac Muscle after Swimming Training in Myocardial-Infarcted Rats. Cell Physiol Biochem 2014;33:657-669.

41 Long G, Wang F, Duan Q, Chen F, Yang S, Gong W, Wang Y, Chen C, Wang DW: Human circulating microRNA-1 and microRNA-126 as potential novel indicators for acute myocardial infarction. Int J Biol Sci 2012;8:811818.

42 Fichtlscherer S, De Rosa S, Fox H, Schwietz T, Fischer A, Liebetrau C, Weber M, Hamm CW, Röxe T, MüllerArdogan M, Bonauer A, Zeiher AM, Dimmeler S: Circulating microRNAs in patients with coronary artery disease. Circ Res 2010;107:677-684.

43 Magenta A, Dellambra E, Ciarapica R, Capogrossi MC: Oxidative stress, microRNAs and cytosolic calcium homeostasis. Cell Calcium 2016;60:207-217. 


\section{Cellular Physiology Cell Physiol Biochem 2016;40:1591-1602 \begin{tabular}{l|l|l|}
\hline DOI: 10.1159/000453209 & $\begin{array}{l}\text { C) 2016 The Author(s). Published by S. Karger AG, Basel } \\
\text { www.karger.com/cpb }\end{array}$ \\
\hline
\end{tabular} \\ Zhu et al.: miR-181a as Biomarker for Acute Myocardial Infarction}

44 Ramasamy S, Velmurugan G, Shanmugha RK, Ramprasath T, Kalpana K: MiRNAs with apoptosis regulating potential are differentially expressed in chronic exercise-induced physiologically hypertrophied hearts. PLoS One 2015;10:e121401.

45 Fichtlscherer S, Zeiher AM, Dimmeler S: Circulating microRNAs: biomarkers or mediators of cardiovascular diseases? Arterioscler Thromb Vasc Biol 2011;31:2383-2390.

46 Sun J, Hartvigsen K, Chou MY, Zhang Y, Sukhova GK, Zhang J, Lopez-Ilasaca M, Diehl CJ, Yakov N, Harats D, George J, Witztum JL, Libby P, Ploegh H, Shi GP: Deficiency of antigen-presenting cell invariant chain reduces atherosclerosis in mice. Circulation 2010;122:808-820.

47 Jaffe AS, Babuin L, Apple FS: Biomarkers in acute cardiac disease: the present and the future. J Am Coll Cardiol 2006;48:1-11.

48 Corsten MF, Dennert R, Jochems S, Kuznetsova T, Devaux Y, Hofstra L, Wagner DR, Staessen JA, Heymans S, Schroen B: Circulating MicroRNA-208b and MicroRNA-499 reflect myocardial damage in cardiovascular disease. Circ Cardiovasc Genet 2010;3:499-506.

49 Hu X, Ma R, Lu J, Zhang K, Xu W, Jiang H, Da Y: IL-23 Promotes Myocardial I/R Injury by Increasing the Inflammatory Responses and Oxidative Stress Reactions. Cell Physiol Biochem 2016;38:2163-2172.

50 Du W, Pan Z, Chen X, Wang L, Zhang Y, Li S, Liang H, Xu C, Zhang Y, Wu Y, Shan H, Lu Y: By targeting Stat3 microRNA-17-5p promotes cardiomyocyte apoptosis in response to ischemia followed by reperfusion. Cell Physiol Biochem 2014;34:955-965.

51 Hu S, Huang M, Li Z, Jia F, Ghosh Z, Lijkwan MA, Fasanaro P, Sun N, Wang X, Martelli F, Robbins RC, Wu JC: MicroRNA-210 as a novel therapy for treatment of ischemic heart disease. Circulation 2010;122:S124-131.

52 Gu Y, Liu Z, Li L, Guo CY, Li CJ, Wang LS, Yang ZJ, Ma WZ, Jia EZ: OLR1, PON1 and MTHFR gene polymorphisms, conventional risk factors and the severity of coronary atherosclerosis in a Chinese Han population. Cell Physiol Biochem 2013;31:143-152.

53 Lerner DJ, Kannel WB: Patterns of coronary heart disease morbidity and mortality in the sexes: a 26-year follow-up of the Framingham population. Am Heart J 1986;111:383-390.

54 Price JF, Fowkes FG: Risk factors and the sex differential in coronary artery disease. Epidemiology 1997;8:584-891.

55 Barzi F, Patel A, Gu D, Sritara P, Lam TH, Rodgers A, Woodward M: Cardiovascular risk prediction tools for populations in Asia. J Epidemiol Community Health 2007;61:115-121.

56 Lloyd-Jones DM, Wilson PW, Larson MG, Beiser A, Leip EP, D'Agostino RB, Levy D: Framingham risk score and prediction of lifetime risk for coronary heart disease. Am J Cardiol 2004;94:20-24.

57 D'Agostino RB Sr, Vasan RS, Pencina MJ, Wolf PA, Cobain M, Massaro JM, Kannel WB: General cardiovascular risk profile for use in primary care: the Framingham Heart Study. Circulation 2008;117:743-753.

58 Mozaffarian D, Benjamin EJ, Go AS, Arnett DK, Blaha MJ, Cushman M, de Ferranti S, Després JP, Fullerton HJ, Howard VJ, Huffman MD, Judd SE, Kissela BM, Lackland DT, Lichtman JH, Lisabeth LD, Liu S, Mackey RH, Matchar DB, McGuire DK, Mohler ER 3rd, Moy CS, Muntner P, Mussolino ME, Nasir K,Neumar RW, Nichol G, Palaniappan L, Pandey DK, Reeves MJ, Rodriguez CJ, Sorlie PD, Stein J, Towfighi A, Turan TN, Virani SS, Willey JZ, Woo D, Yeh RW, Turner MB: Heart disease and stroke statistics--2015 update: a report from the American Heart Association. Circulation 2015;131:e29-322.

59 Freedman JE, Gerstein M, Mick E, Rozowsky J, Levy D, Kitchen R, Das S, Shah R, Danielson K, Beaulieu L, Navarro FC, Wang Y, Galeev TR, Holman A, Kwong RY, Murthy V, Tanriverdi SE, Koupenova-Zamor M, Mikhalev E, Tanriverdi K: Diverse human extracellular RNAs are widely detected in human plasma. Nat Commun 2016;7:11106.

60 Sun X, Icli B, Wara AK, Belkin N, He S, Kobzik L, Hunninghake GM, Vera MP, MICU Registry, Blackwell TS, Baron RM, Feinberg MW: MicroRNA-181b regulates NF-kappaB-mediated vascular inflammation. J Clin Invest 2012;122:1973-1990.

61 Sonkoly E, Stahle M, Pivarcsi A: MicroRNAs and immunity: novel players in the regulation of normal immune function and inflammation. Semin Cancer Biol 2008;18:131-140. 